\title{
Leukemia inhibitory factor protects photoreceptor cone cells against oxidative damage through activating JAK/STAT3 signaling
}

\author{
Shuqian Dong ${ }^{1}$, Fangyuan Zhen ${ }^{1}$, Huizhuo $\mathrm{Xu}^{2}$, Qiuming $\mathrm{Li}^{1}$, Jiajia Wang ${ }^{3}$ \\ ${ }^{1}$ Department of Ophthalmology, The First Affiliated Hospital of Zhengzhou University, Henan Provincial Ophthalmic Hospital, Zhengzhou, China; \\ ${ }^{2}$ Department of Ophthalmology, Xiangya Hospital of Central South University, Changsha, China; ${ }^{3}$ Department of Laboratory Medicine, Sichuan \\ Academy of Medical Sciences \& Sichuan Provincial People's Hospital, Chengdu, China \\ Contributions: (I) Conception and design: Q Li, J Wang; (II) Administrative support: None; (III) Provision of study materials or patients: None; (IV) \\ Collection and assembly of data: S Dong, F Zhen, H Xu; (V) Data analysis and interpretation: S Dong; (VI) Manuscript writing: All authors; (VII) \\ Final approval of manuscript: All authors. \\ Correspondence to: Dr. Jiajia Wang. Department of Laboratory Medicine, Sichuan Academy of Medical Sciences \& Sichuan Provincial People's \\ Hospital, Chengdu 610072, China. Email: xywjj18@163.com; Dr. Qiuming Li. Department of Ophthalmology, The First Affiliated Hospital of \\ Zhengzhou University, Henan Provincial Ophthalmic Hospital, Zhengzhou 450052, China. Email: liqiuming63@163.com.
}

Background: The present study aimed to investigate the protective role of leukemia inhibitory factor (LIF) against oxidative damage in photoreceptor cone cells.

Methods: In vivo, dark-adapted mice were injected with LIF or phosphate-buffered saline (PBS) intravitreously prior to being exposed to 5,000 lux bright light to determine the protective effect of LIF against light damage in cone cells. Oxidative damage to cone cells was analyzed using electroretinograms, immunostaining, Western blotting and reverse transcription quantitative polymerase chain reaction (RTqPCR). In vitro, $661 \mathrm{~W}$ cells were pretreated with $5 \mathrm{ng} / \mathrm{mL}$ of LIF with or without $50 \mu \mathrm{M}$ of signal transducer and activator of transcription 3 (STAT3) inhibitor S3I201 for $1 \mathrm{~h}$ prior to treatment with $1 \mathrm{mM} \mathrm{H}_{2} \mathrm{O}_{2}$; cell survival, apoptosis, the oxidative stress index, and the activation of STAT3, extracellular signal-regulated kinase (ERK1/2), and AKT were subsequently determined.

Results: In vivo, light induction damaged the function and morphology of cone cells, and LIF was observed to protect cone cells from this light damage. Moreover, the activation of the Janus tyrosine kinase (JAK)/ STAT3 signaling pathway and the subsequent changes in apoptosis and proliferation-related genes were found to be involved in the protective effect of LIF against light-induced retinal damage. In the $\mathrm{H}_{2} \mathrm{O}_{2}$ induced $661 \mathrm{~W}$ cell model, $\mathrm{H}_{2} \mathrm{O}_{2}$ increased cellular apoptosis rates, the expression levels of Bcl-2-associated $\mathrm{X}$-protein (BAX) and cleaved caspase 3, reactive oxygen species (ROS) production, and malondialdehyde content, while decreasing the cell viability, and Bcl-2, superoxide dismutase, catalase, and glutathione peroxidase activity. LIF was observed to block these events; however, the administration of the STAT3 inhibitor S3I201 reversed the beneficial effects of LIF on $\mathrm{H}_{2} \mathrm{O}_{2}$-triggered apoptosis and ROS production.

Conclusions: In conclusion, the present study suggested that LIF may relieve oxidative damage in cone cells through suppressing apoptosis and oxidative stress by targeting the STAT3 signaling pathway.

Keywords: Leukemia inhibitory factor; cone cells; apoptosis; signal transducer and activator of transcription 3 (STAT3)

Submitted Nov 19, 2020. Accepted for publication Jan 15, 2021.

doi: $10.21037 /$ atm-20-8040

View this article at: http://dx.doi.org/10.21037/atm-20-8040 


\section{Introduction}

Age-related macular degeneration (AMD) is a retinal degenerative disease, which is known to be a leading cause of severe visual impairment (1). The retinal photic injury of AMD is typically associated with excessive light exposure and the subsequent induction of oxidative stress $(2,3)$. Upon exposure to light, photochemical damage to the retina is initiated, resulting in increases in reactive oxygen species (ROS) and decreased levels of superoxide dismutase (SOD), which can then progress into the pathology of AMD (4-6). The degeneration of retinal pigment epithelial (RPE) cells is considered to be the originating factor contributing to AMD (7). This subsequently promotes the degeneration of photoreceptor cells and thus, leads to vision loss (8). Furthermore, accumulating evidence has suggested that oxidative stress can induce cell death in photoreceptors and RPE cells due to the generation of ROS, such as hydrogen peroxide $\left(\mathrm{H}_{2} \mathrm{O}_{2}\right)$ and superoxide $\left(\mathrm{O}_{2}^{-}\right)(9,10)$. Indeed, phototoxicity in the retina has been demonstrated to exert significant damage to photoreceptors $(11,12)$.

Leukemia inhibitory factor (LIF) is a member of the interleukin 6 (IL-6) cytokine family; all members have their own receptors but share the common transmembrane receptor subunit gp130. Activated gp130 induces signaling through the Janus kinase (JAK) and signal transducer and activator of transcription (STAT) pathway, the mitogenactivated protein kinase (MAPK) pathway, and the PI3K pathway $(13,14)$. Among these signaling events, JAK/ STAT3 pathway had been considered to be the most important, which could activate the upregulation of several genes important for neuroprotection. In the early 1990s, the neuroprotective effect of LIF was recognized in cultured neuronal cells and a variety of animal models, and this effect was reported to occur in the retina following light damage $(15,16)$. For example, the expression levels of LIF in the retina were found to be increased following the exposure to excessive light (17), whereas the lack of LIF signaling led to the increased death of photoreceptors in a light-induced $\mathrm{LIF}^{-/-}$mice model (18). Other studies have reported that the intravitreal injection of recombinant LIF could protect photoreceptors against light damage, in which the protective effects occurred through the LIFR/gp130 receptor complex and the subsequent activation of the JAK/ STAT3 signaling pathway (19). These findings suggest that LIF may be a potential treatment for retinal degeneration.

In vertebrates, the well-organized structure of the retina includes seven neuronal cell types and one glial cell type. Approximately $70 \%$ of the cells in the retina are photoreceptors, which can be classified into two types: rods and cones (20). In addition to the neuronal cells in the retina, retinal glia cells, also known as Müller cells, are also present. Under numerous conditions of pathogenic stimuli, Müller cells become activated and respond to injury by producing multiple survival or inflammatory factors (21). Among these, LIF is a prominent protein that promotes photoreceptor survival (22). Previous studies have revealed that cones are less susceptible to light damage compared with rods, but cones may also die following a delayed response due to a bystander effect that may include reduced metabolic support $(23,24)$. Due to rods being more common than cones, with $\sim 100$ million rod cells compared with $\sim 7$ million cone cells, the mechanisms behind lightinduced damage in rods has been well investigated; however, accumulating evidence indicates that lightinduced damage also affects cones, detailed mechanisms of which remain largely unclear. Therefore, the current study aimed to evaluate the protective effect of LIF against oxidative damage in photoreceptor cone cells and to clarify the possible mechanisms which underlie it.

We present the following article in accordance with the ARRIVE reporting checklist (available at http://dx.doi. org/10.21037/atm-20-8040).

\section{Methods}

\section{Animals studies}

A total of $45 \mathrm{BALB} / \mathrm{c}$ mice (age, 5-6 weeks; weight, 15-18 g) were obtained from the Shanghai Laboratory Animal Center. The mice were divided into 5 groups: (I) a normal control group (n=15), (II) a vehicle control [phosphatebuffered saline (PBS)] group without light damage $(n=15)$, (III) a LIF treatment group without light damage $(\mathrm{n}=15)$, (IV) a vehicle control (PBS) group with light damage $(\mathrm{n}=15)$; and $(\mathrm{V})$ a LIF treatment group with light damage $(\mathrm{n}=15)$. The animals were housed at The First Affiliated Hospital of Zhengzhou University at $25^{\circ} \mathrm{C}$ in a 12 -h lightdark cycle. All procedures were in accordance with the National Institutes of Health Guide for the Care and Use of Laboratory Animals. Ethical approval was obtained from the Ethics Committee of Zhengzhou University.

The mice were anesthetized with an intraperitoneal injection of $10 \mathrm{mg} / \mathrm{g}$ if xylazine and $70 \mathrm{mg} / \mathrm{g}$ of ketamine (Pfizer Inc., New York, NY, USA), and subsequently injected with $1 \mu \mathrm{L}$ of LIF solution $(0.4 \mathrm{~g} / \mathrm{L}$; Abcam, 
Table 1 Parameters of ERG

\begin{tabular}{lccc}
\hline Parameter & Pho 2000 & M-cone & S-cone \\
\hline Flash cycle & Single & Single & Single \\
Pulse frequency $(\mathrm{Hz})$ & 1 & 1 & 0 \\
Pulse period $(\mathrm{ms})$ & 0 & $13(\mathrm{P})$ & Green \\
Pulse intensity $\left(\mathrm{cd} \cdot \mathrm{s} / \mathrm{m}^{2}\right)$ & $2,000(\mathrm{P})$ & $50(\mathrm{P})$ & 1 \\
Pulse color & Xeno & Blue \\
Background intensity $\left(\mathrm{cd} \cdot \mathrm{s} / \mathrm{m}^{2}\right)$ & $50(\mathrm{P})$ & $50(\mathrm{P})$ &
\end{tabular}

Cambridge, UK) or PBS into the vitreous chamber using a 36-gauge needle. For each mouse, the right eye was injected with LIF, whereas the left eye was injected with PBS and served as the control. For light exposure, mice were adapted in the dark for $12 \mathrm{~h}$ prior to being exposed to 5,000 lux bright light for $4 \mathrm{~h}$ from 8:00 pm to 12:00 am. All mice were allowed to recover for $24 \mathrm{~h}$ in the dark following light exposure and were then housed in normal lighting for 7 days before analysis by electroretinography (ERG), immunofluorescence, and western blotting.

\section{Electroretinography (ERG)}

Flash ERGs were recorded with an Espion E2 ERG system (Diagnosys, Lowell, MA, USA). Briefly, 5 mice/ group were dark-adapted overnight and prepared for ERG recording in dim red light. Each mouse was anesthetized under dim red light, and pupils were dilated with one drop of $10 \%$ phenylephrine (Pfizer Inc.). The body temperature of the mice was maintained close to $37^{\circ} \mathrm{C}$ with a waterheating pad. Animals were placed inside a Ganzfeld illuminating sphere with a gold electrode placed on the cornea. The reference electrode was hooked in the mouth and a ground wire was attached to the tail. After light adaptation (white light; $50 \mathrm{~cd} / \mathrm{m}^{2}$ ) for $10 \mathrm{~min}$, the function of whole cone cells, M-cone cells, and S-cone cells were detected; the parameters used are listed in Table 1. The amplitude of the a-wave was measured from the baseline to the a-wave trough. The amplitude of the b-wave was measured from the trough of the a-wave to the peak of the b-wave.

\section{Morphologic analysis}

Mice were sacrificed by displacement of air with $100 \%$ $\mathrm{CO}_{2}$ with the eyes being marked on the superior side $(\mathrm{n}=5 /$ group). The eyes were subsequently enucleated and fixed overnight in PerFix (20\% isopropanol, 2\% trichloroacetic acid, $4 \%$ paraformaldehyde and $2 \%$ zinc chloride) and then placed in $70 \%$ ethanol. The eyes were then embedded in paraffin, and $5-\mu \mathrm{m}$ sagittal sections were cut through the optic disc. To assess the effect of the treatment on the retinal cells, the paraffin-embedded sections were rehydrated, blocked, and incubated with a rabbit antimouse M-cone or S-cone polyclonal antibody (Santa Cruz Biotechnology, Inc., Dallas, TX, USA). Following the primary antibody incubation, sections were incubated with Alexa Fluor 594-conjugated goat anti-rabbit IgG secondary antibody (Molecular Probes; Thermo Fisher Scientific, Inc., USA); for the negative control, the primary antibody was replaced with PBS.

\section{Reverse transcription-quantitative polymerase chain reaction (RT-qPCR)}

Mice $(\mathrm{n}=5)$ were sacrificed with exposure to $\mathrm{CO}_{2}$, and the retina of the eyes were harvested and preserved in liquid nitrogen for subsequent experimentation. Total RNA was extracted from the retina using TRIzol $^{\circledR}$ reagent (Thermo Fisher Scientific, Inc.), according to the manufacturer's protocol. Total RNA was reverse transcribed into cDNA using an RT kit (Thermo Fisher Scientific, Inc.). qPCR was subsequently performed using a SYBR ${ }^{\circledR}$ Green Premix Ex Taq $^{\text {TM }}$ Real-time PCR kit (Takara Bio USA, Inc., Shiga, Japan) and an ABI 7500 thermocycler (Applied Biosystems; Thermo Fisher Scientific, Inc.). The following thermocycling conditions were used for the qPCR: initial denaturation at $95^{\circ} \mathrm{C}$ for $10 \mathrm{~min}$; followed by 40 cycles of denaturation at $95{ }^{\circ} \mathrm{C}$ for $20 \mathrm{sec}$, annellation at $63{ }^{\circ} \mathrm{C}$ for $20 \mathrm{sec}$, and extension at $72{ }^{\circ} \mathrm{C}$ for $20 \mathrm{~s}$. Expression levels were quantified using the $2^{-\Delta \Delta \mathrm{Cq}}$ method and GAPDH was used as the internal loading control. 


\section{Cell culture and $\mathrm{H}_{2} \mathrm{O}_{2}$ treatment}

The murine photoreceptor-derived $661 \mathrm{~W}$ cell line was purchased from the American Type Culture Collection. The cells were cultured in Dulbecco's Modified Eagle Medium (DMEM) (Merck KGaA, St. Louis, MO, USA), supplemented with $10 \%$ fetal bovine serum (FBS; Merck KGaA), $100 \mathrm{U} / \mathrm{mL}$ of penicillin, and $50 \mathrm{U} / \mathrm{mL}$ of streptomycin, and maintained in a $5 \% \mathrm{CO}_{2}$-humidified incubator at $37^{\circ} \mathrm{C}$. For $\mathrm{H}_{2} \mathrm{O}_{2}$ exposure, $661 \mathrm{~W}$ cells were serum-starved for $1 \mathrm{~h}$ prior to treatment with $\mathrm{H}_{2} \mathrm{O}_{2}$. For drug treatment, $661 \mathrm{~W}$ cells were pretreated with $5 \mathrm{ng} / \mathrm{mL}$ LIF for $1 \mathrm{~h}$ prior to treatment with $1 \mathrm{mM} \mathrm{H}_{2} \mathrm{O}_{2}$, with or without pretreatment with $50 \mu \mathrm{M}$ STAT3 inhibitor S3I201 (Merck KGaA) for $1 \mathrm{~h}$ prior to the treatment with LIF and $\mathrm{H}_{2} \mathrm{O}_{2}$. Cell viability; apoptosis; the levels of oxidative stress, including ROS, malondialdehyde (MDA), SOD, catalase (CAT), and glutathione peroxidase (GPx); and the phosphorylation of extracellular signal-regulated kinases (ERK)1/2, AKT and STAT3; were subsequently determined.

\section{Cell viability assay}

Following the treatment of cells, $10 \mu \mathrm{L}$ of MTT solution $(5 \mathrm{mg} / \mathrm{mL})$ was added to each well of the 96 -well plate. Following incubation for $4 \mathrm{~h}$, the medium was removed and $150 \mu \mathrm{L}$ of dimethyl sulfoxide (DMSO) was added. The absorbance value at $570 \mathrm{~nm}$ was read using a microplate reader (Omega Bio-Tek, Inc., Norcross, GA, USA).

\section{Western blotting}

Membranes were incubated with the following antibodies purchased from Cell Signaling Technology, Inc: anti-Bcl-2 (cat. no. 3498), anti-Bax (cat. no. 2772), anti-cleaved caspase 3 (cat. no. 9664), anti-phosphorylated (phospho)-p44/42 MAPK (ERK1/2; Thr202/Tyr204; cat. no. 4370), anti-p44/42 MAPK (137F5; cat. no. 4695), anti-phosphoSTAT3 (Tyr705; cat. no. 9145), anti-STAT3 (79D7; cat. no. 4904), anti-phospho-AKT (Ser473; cat. no. 4060), antiAKT (cat. no. 9272), and anti-GAPDH (cat. no. 5174). Following the primary antibody incubation, a horseradish peroxidase-conjugated immunoglobin G secondary antibody was subsequently incubated with the membrane. Protein expression levels were quantified using ImageJ software (National Institutes of Health). Following the normalization to GAPDH, the average band intensity value obtained from the untreated samples was used to calculate the fold change in protein expression levels for the treated samples.

\section{Oxidative stress assay}

Cells were treated as described above, and the production of intracellular ROS, the content of MDA, and the activity of SOD was determined according to the manufacturer's protocol (Cell Biolabs, Inc., San Diego, CA, USA). The activities of CAT and GPx were determined according to the manufacturer's protocol (Cayman Chemical Company, Ann Arbor, MI, USA).

\section{Apoptosis analysis}

Apoptosis analysis was performed using a cell death detection ELISA ${ }^{\text {plus }}$ kit (Roche Diagnostics GmbH, Basel, Switzerland), according to the manufacturer's protocol. The optical density $\left(\mathrm{OD}_{405} \mathrm{~nm}\right)$ was determined using a microplate reader (Bio-Rad Laboratories, Inc., Hercules, CA, USA).

\section{Statistical analysis}

Statistical analysis was performed using SPSS version 22.0 software (IBM Corp., Armonk, NY, USA) and GraphPad Prism version 5.0 software (GraphPad Software, Inc., San Diego, CA, USA). Data are presented as the mean \pm SD. Statistical differences were determined using a Student's $t$-test. A P value $<0.05$ was considered to indicate a statistically significant difference.

\section{Results}

\section{Neuroprotective effect of LIF against light damage in the retina}

To determine whether or not the intravitreal injection of LIF prior to light damage protected photoreceptor function and morphology, a light-induced damage mouse model was established. To analyze the function of cone cells, the b-wave amplitude was measured using ERG, which determines the functional integrity of the cone cells in response to light. Under stimulation with white, green, and blue light, the b-wave amplitudes of all groups exhibited consistent trends. The eyes from the PBS and LIF-treated groups demonstrated no significant changes in the b-wave amplitudes compared with the normal 
controls ( $>>0.05$; Figure 1). Upon light-induced damage, the b-wave amplitudes in eyes treated with PBS were significantly decreased compared with the PBS controls $(\mathrm{P}<0.05$; Figure 1). Conversely, following the exposure to light damage, the b-wave amplitudes in eyes treated with LIF were significantly increased compared with eyes treated with $\mathrm{PBS}(\mathrm{P}<0.05$; Figure 1). These data suggested that the intravitreous injection of PBS had no significant effect on the cone cells, but the light-induced damage that affected the function of cone cells may be protected by LIF treatment.

\section{Morphological changes of cone cells in the retina following LIF treatment}

In the retina, although cone cells are less sensitive to light compared with rod cells, they can detect color. There are two types of pigment in mice: M-cones that absorb green light, and $\mathrm{S}$-cones that absorb blue light. The extracellular segments of $\mathrm{M}$-cones and S-cones in the PBS and LIF groups were tapered and arranged in sequence, with no significant changes observed in the quantity and morphology (Figure 2); however, the quantity of M-cones and $\mathrm{S}$-cones in the eyes exposed to light damage were significantly reduced, especially in the eyes treated with PBS. In the eyes treated with PBS followed by the exposure to light damage, M-cones and S-cones were observed to be clustered in spots or fragments. This morphological change could be partially blocked following the pretreatment of the eyes with LIF. In conclusion, the intravitreous injection of PBS or LIF had no significant effect on the morphology of cone cells, but the induction of light altered both the quantity and morphology of cone cells, with the LIF pretreatment being observed to partially protect cone cells from light-induced damage.

\section{Protective effect of LIF in the retina was associated with STAT3 activation}

LIF can activate gp130 and phosphorylate downstream signaling pathways, such as JAK/STAT3, MAPK/ERK, or PI3K/AKT. To determine whether the activation of these signaling proteins participated in the protective effect of LIF against light-induced retinal damage, phosphorylated STAT3 on Tyr705, ERK1/2 and AKT on Ser473 expression levels in the retina of each group were analyzed. LIF markedly increased the phosphorylation of STAT3 compared with the normal controls or the PBS group (Figure 3).
Eyes that were exposed to light damage following PBS treatment had significantly increased phosphorylation levels of STAT3, ERK1/2, and AKT Ser473 compared with the PBS group $(\mathrm{P}<0.05)$. When compared with the eyes exposed to light damage followed by PBS treatment, LIF pretreatment increased the phosphorylation of STAT3 significantly $(6.5 \pm 2.9$ vs. $14.7 \pm 3.2$ fold, respectively; Figure 3). As for p-ERK $1 / 2$ and p-AKT Ser473, no significant differences were found between the LIF and PBS pretreatment following light-induced damage. In conclusion, these findings suggested that STAT3 activation may contribute to the protective effect of LIF against lightinduced retinal damage.

\section{Protective effect of LIF in the retina was related to the altered expression levels of apoptosis and proliferation- related genes}

Based on the above findings, it was hypothesized that the JAK/STAT3 signaling pathway may be strongly activated in the retina following LIF pretreatment prior to light exposure. In fact, the activation of the JAK/STAT3 signaling pathway may be involved in several cellular functions, including differentiation regulation, cell cycle arrest, and apoptosis. To investigate the complex protective mechanism of LIF against light-induced oxidative damage, the expression levels of the following genes were detected in the retina: antioxidant genes, SOD1, CAT and GPx1; major genes involved in the JAK/STAT3 pathway, STAT3, SOCS3 and $\mathcal{A} A K 3$; apoptosis-related genes, BCL2A1D, $A T F 3$, and DDIT4; and proliferation-related genes, GADD45A, GZMM, and PARP1. Prior to the stimulation of light damage, LIF pretreatment was observed to increase the expression levels of the antioxidant genes SOD1, CAT and GPx1, along with STAT3, SOCS3, and FAK3 (Figure 4), which confirmed the participation of the JAK/STAT3 signaling pathway in the protective effect of LIF against light-induced oxidative damage. Furthermore, increased expression levels of the anti-apoptotic genes BCL2A1D and $A T F 3$, and the pro-proliferative genes, GADD45A and PARP12, along with the decreased expression levels of the pro-apoptotic gene DDIT4 and the anti-proliferative gene $G Z M M$, were found in the retinas pretreated with LIF prior to light-induced damage. Altogether, these findings suggested that LIF may exert its protective effect against light damage through increasing the expression levels of anti-apoptotic and pro-proliferative genes and decreasing the expression levels of pro-apoptotic and anti-proliferative genes. 
A

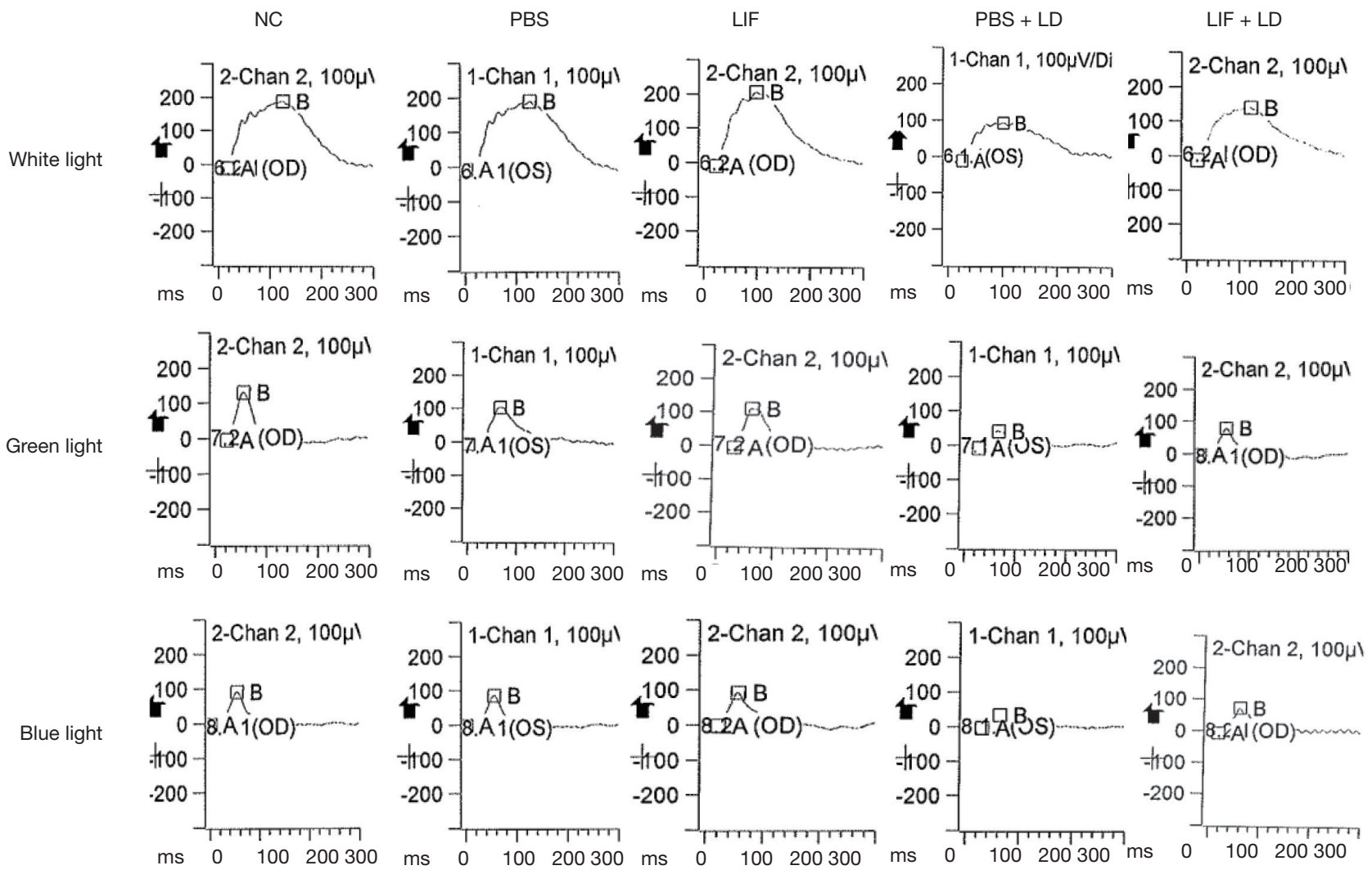

B

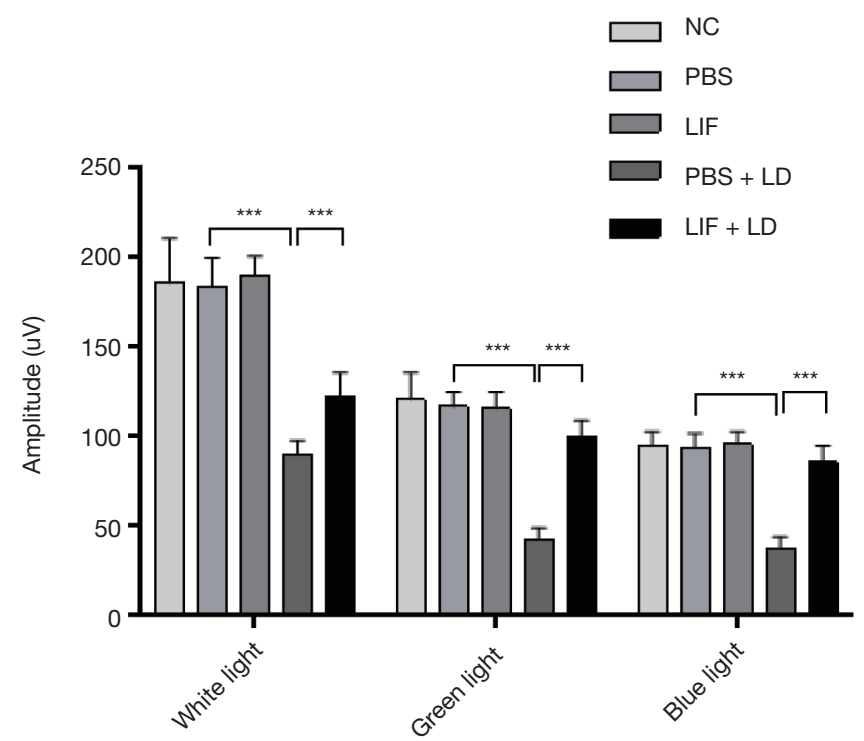

Figure 1 LIF protects the function of cone cells in the retina against light damage. (A) The function of cone cells in the retina was analyzed using ERGs and representative ERG images of the PBS, LIF, PBS + LD, and LIF + LD. (B) Quantification of the amplitudes of $b$ waves in the PBS, LIF, PBS + LD, and LIF + LD groups. Data are presented as the mean \pm SD. ${ }^{* *} \mathrm{P}<0.001$. ERG, electroretinogram; NC, normal control; LIF, leukemia inhibitory factor; LD, light damage; $\mathrm{H}_{2} \mathrm{O}_{2}$, hydrogen peroxide. 


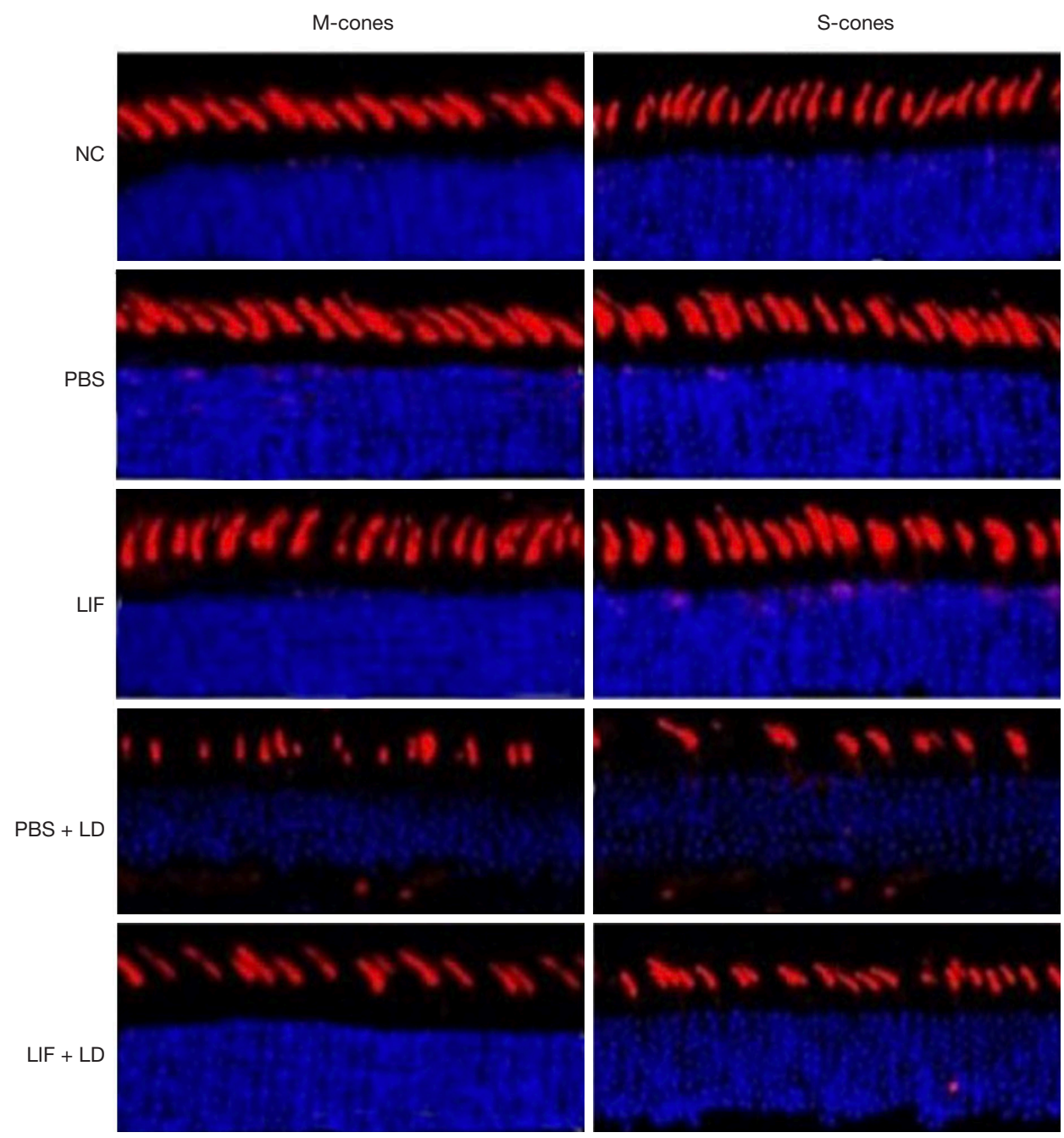

Figure 2 LIF protects the morphology of cone cells in the retina against LD. Representative images for M-cones and S-cones in the PBS, LIF, PBS + LD, and LIF + LD treatment groups. NC, normal control; LIF, leukemia inhibitory factor; LD, light damage; H2O2, hydrogen peroxide.

\section{LIF protected $661 \mathrm{~W}$ cells against $\mathrm{H}_{2} \mathrm{O}_{2}$-induced apoptosis}

To further study the protective mechanism of LIF in cone cells, $661 \mathrm{~W}$ cells and an $\mathrm{H}_{2} \mathrm{O}_{2}$-induced oxidative damage model was used. To identify the role of LIF in $\mathrm{H}_{2} \mathrm{O}_{2}$ induced cell damage, cell viability was first examined. The treatment of $661 \mathrm{~W}$ cells with $1 \mathrm{mM} \mathrm{H}_{2} \mathrm{O}_{2}$ for $12 \mathrm{~h}$ led to an $\sim 50 \%$ loss in cell viability (Figure $5 A$ ). By contrast, treatment with $5 \mathrm{ng} / \mathrm{mL}$ LIF followed by $1 \mathrm{mM} \mathrm{H}_{2} \mathrm{O}_{2}$ led to increased cell survival in $661 \mathrm{~W}$ cells $(\mathrm{P}<0.05)$. Cell apoptosis was subsequently detected, which indicated that while $\mathrm{H}_{2} \mathrm{O}_{2}$ stimulation induced cell apoptosis, LIF treatment markedly decreased the levels of $\mathrm{H}_{2} \mathrm{O}_{2}$-induced cell apoptosis $(\mathrm{P}<0.05)$ (Figure 5B). Furthermore, LIF pretreatment increased the expression levels of the anti-apoptotic protein Bcl-2, and decreased the expression levels of the pro-apoptotic protein $\mathrm{BAX}$, the downstream protein cleaved caspase 3, and the ratio of BAX/Bcl-2 following $\mathrm{H}_{2} \mathrm{O}_{2}$ stimulation in $661 \mathrm{~W}$ cells (Figure 5C-E). Collectively, these findings suggested that LIF may alleviate $\mathrm{H}_{2} \mathrm{O}_{2}$-induced apoptosis in $661 \mathrm{~W}$ cells.

\section{LIF inbibited oxidative stress in $\mathrm{H}_{2} \mathrm{O}_{2}$-stimulated $661 \mathrm{~W}$ cells}

Oxidative stress serves an important role in the $\mathrm{H}_{2} \mathrm{O}_{2}$ induced apoptosis of $661 \mathrm{~W}$ cells. To investigate the 
A

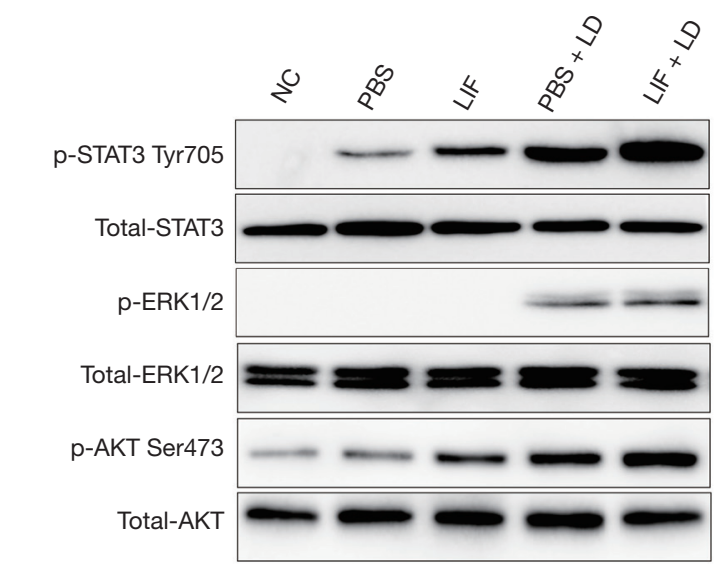

B

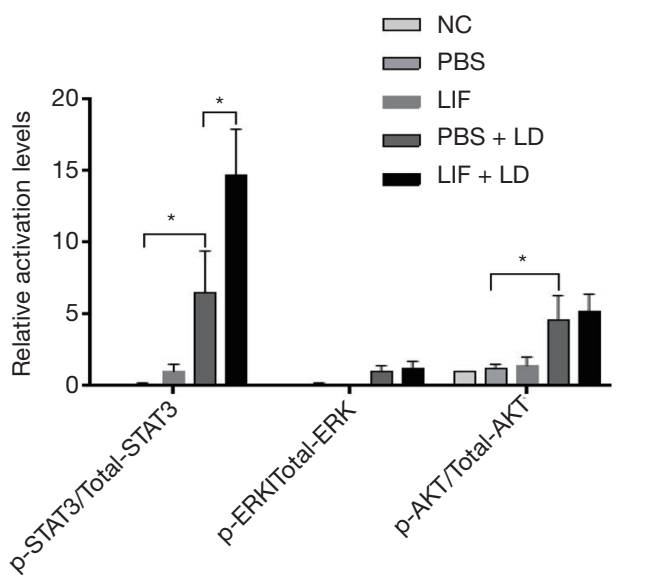

Figure 3 Activation of STAT3 is associated with the protective effects of LIF in the retina. (A) The retina of mice under various treatments was collected, and the p-STAT3, p-ERK1/2, and p-AKT expression levels were detected using western blotting. (B) Semiquantification of the activation of STAT3, ERK1/2, and AKT from part A. Data are presented as the mean $\pm \mathrm{SD} .{ }^{*} \mathrm{P}<0.05$. NC, normal control; LIF, leukemia inhibitory factor; LD, light damage; $\mathrm{p}$, phosphorylated; $\mathrm{H}_{2} \mathrm{O}_{2}$, hydrogen peroxide.

potential role of LIF in $\mathrm{H}_{2} \mathrm{O}_{2}$-induced oxidative stress, the changes to the oxidative index (ROS, MDA, SOD, CAT, and GPx levels) in $\mathrm{H}_{2} \mathrm{O}_{2}$-stimulated $661 \mathrm{~W}$ cells were evaluated. $\mathrm{H}_{2} \mathrm{O}_{2}$ stimulation significantly increased the production of ROS, whereas LIF treatment diminished the increased production of ROS observed in response to $\mathrm{H}_{2} \mathrm{O}_{2}$ (Figure 6A). Notably, LIF treatment also attenuated $\mathrm{H}_{2} \mathrm{O}_{2}$-induced MDA content (Figure $6 \mathrm{~B}$ ). In addition, the activities of the antioxidant enzyme SOD, CAT and GPx were evaluated; in response to $\mathrm{H}_{2} \mathrm{O}_{2}$ treatment, there was significantly decreased activity; however, this decrease in activity was blocked by LIF treatment (Figure 6C,D,E).
Taken together, these data indicated that LIF may exert an antioxidant effect, which may protect against $\mathrm{H}_{2} \mathrm{O}_{2}$-induced oxidative damage.

\section{LIF exerted a protective effect against $\mathrm{H}_{2} \mathrm{O}_{2}$-induced damage through targeting the STAT3 signaling pathway}

To further investigate the potential protective mechanism of LIF against oxidative damage in $\mathrm{H}_{2} \mathrm{O}_{2}$-stimulated $661 \mathrm{~W}$ cells, phosphorylated (p)-STAT3 Tyr705, p-ERK1/2, and p-AKT Ser473 expression levels were detected. Compared with $\mathrm{H}_{2} \mathrm{O}_{2}$-treated cells, the expression levels of p-STAT3 Tyr705 were significantly increased in $661 \mathrm{~W}$ cells treated with $5 \mathrm{ng} / \mathrm{mL}$ LIF followed by $1 \mathrm{mM} \mathrm{H}_{2} \mathrm{O}_{2}(\mathrm{P}<0.05$; Figure $7 A, B)$. No significant changes were observed in the activation of ERK1/2 and AKT Ser473 compared with $\mathrm{H}_{2} \mathrm{O}_{2}$-treated cells $(\mathrm{P}>0.05)$. Subsequently, to confirm the protective role of LIF-induced STAT3 against oxidative damage, $661 \mathrm{~W}$ cells were pre-incubated with the STAT3 inhibitor S3I201 for $1 \mathrm{~h}$ prior to treatment with LIF and $\mathrm{H}_{2} \mathrm{O}_{2}$. It was observed that the administration of S3I201 markedly abrogated the protective effects of LIF on $\mathrm{H}_{2} \mathrm{O}_{2}-$ triggered apoptosis (Figure $7 C, D$ ). In addition, the inhibition of STAT3 significantly eliminated the beneficial effects of LIF over ROS production in response to $\mathrm{H}_{2} \mathrm{O}_{2}$ (Figure $7 E$ ). These findings suggested that LIF may exert protective effects against $\mathrm{H}_{2} \mathrm{O}_{2}$-induced apoptosis and oxidative stress through targeting, at least in part, the STAT3 signaling pathway.

\section{Discussion}

Photoreceptor cells are sensory neurons in the eye that absorb light to stimulate vision, and damage to these photoreceptors can lead to permanent blindness (25). Upon exposure to prolonged periods of bright light, oxidative damage and subsequent cell death can occur in photoreceptors. Numerous studies have demonstrated that the exposure to excessive light leads to a significant increase in the expression levels of LIF, basic fibroblast growth factor (bFGF) and ciliary neurotrophic factor (CNTF) $(26,27)$. In fact, some studies have also reported that the exogenous injection of these factors can protect photoreceptors from light-induced damage $(28,29)$; however, it remains relatively unclear whether LIF can protect photoreceptor cone cells from light damage.

In the present study, an in vivo light-damage model was created by placing mice under light stress 2 days 

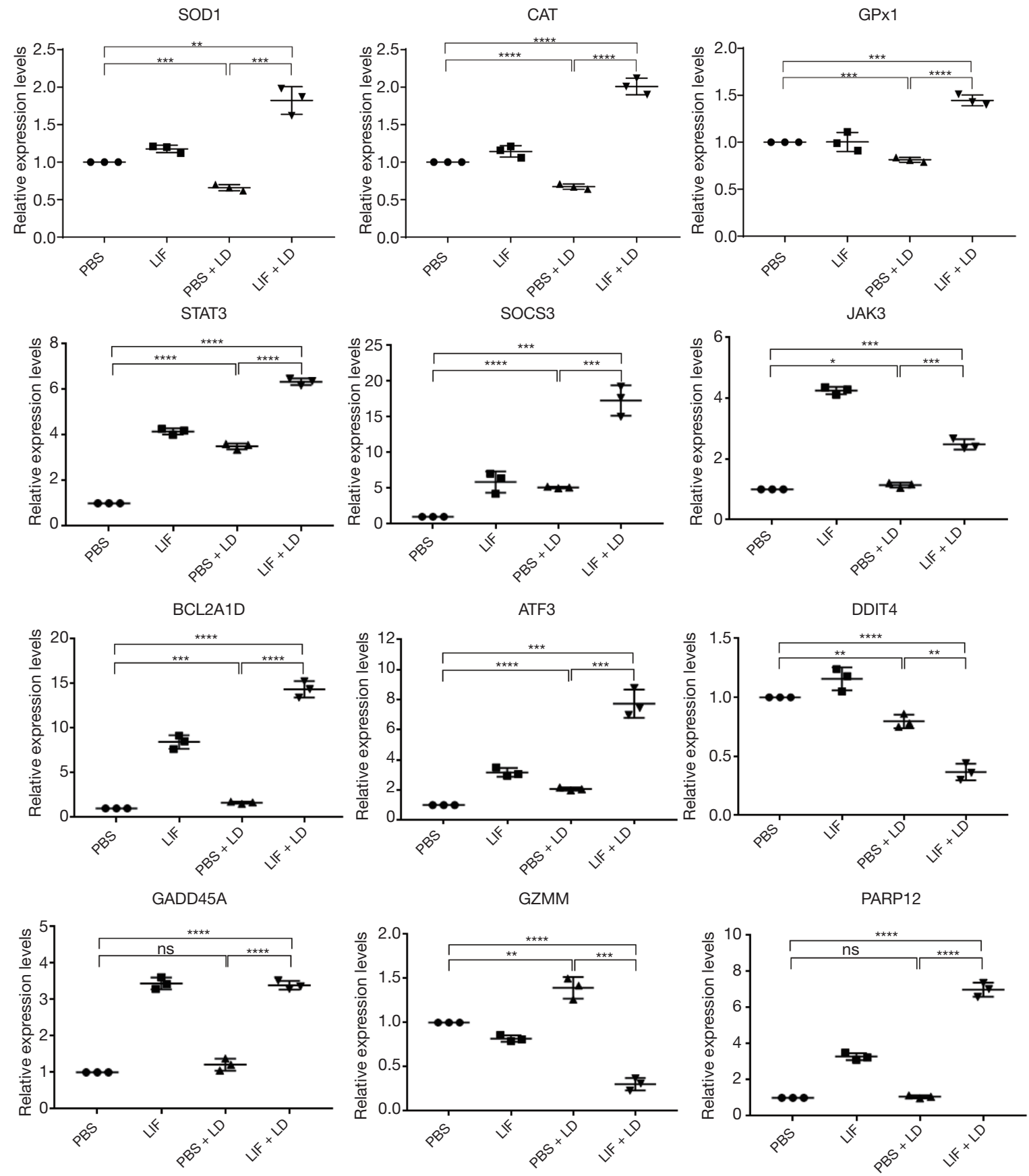

Figure 4 Changes in the expression levels of oxidative stress, apoptosis, and proliferation-related genes in the retina following the pretreatment with LIF prior to LD. The retina of mice under various treatments were collected and the expression levels of $S O D$, $C A T$, GPx1, STAT3, SOCS3, FAK3, BCL2A1D, ATF3, DDIT4, GADD45A, GZMM, and PARP12 were analyzed. Data are presented as the mean \pm SD. Each data point was normalized to the PBS group. ${ }^{*} \mathrm{P}<0.05,{ }^{* *} \mathrm{P}<0.01,{ }^{* * *} \mathrm{P}<0.001,{ }^{* * *} \mathrm{P}<0.0001$. NC, normal control; LIF, leukemia inhibitory factor; LD, light damage; p, phosphorylated; $\mathrm{H}_{2} \mathrm{O}_{2}$, hydrogen peroxide; $S O D$, superoxidase dismutase; CAT, catalase; GP 1 , glutathione peroxidase 1; STAT3, signal transducer and activator of transcription 3; SOCS3, suppressor of cytokine signaling 3; fAK3, Janus kinase 3; BCL2A1D, B cell leukemia/lymphoma 2-related protein A1d; ATF3, activating transcription factor 3; DDIT4, DNA-damageinducible transcript 4; GADD45A, growth arrest and DNA damage inducible alpha; GZMM, granzyme M; PARP12, poly [ADP-ribose] polymerase 12 . 
A

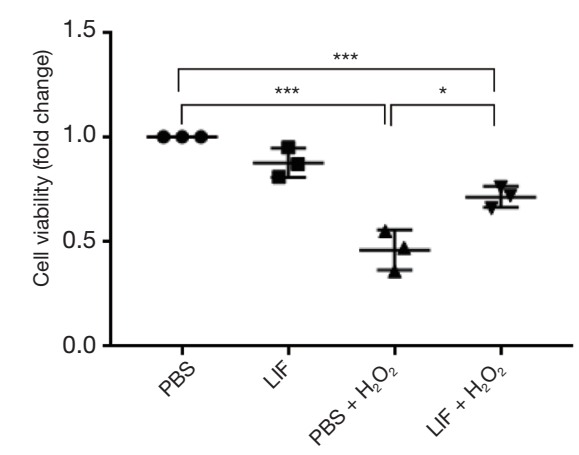

D

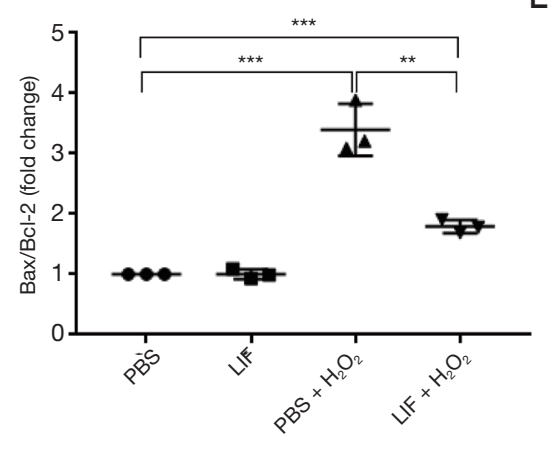

B

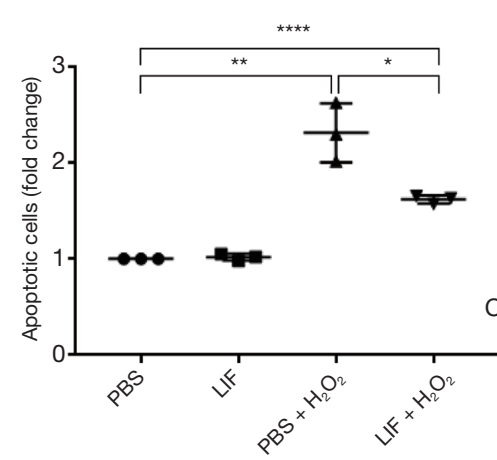

E

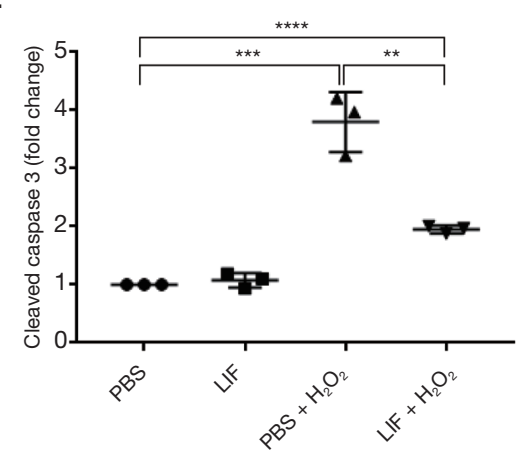

C

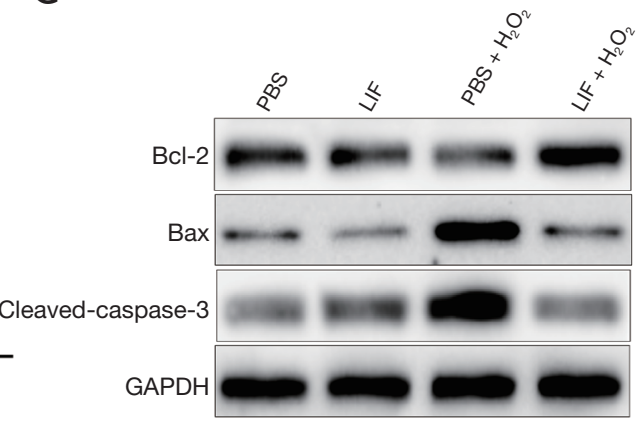

Figure 5 Effects of LIF on H2O2-triggered apoptosis in $661 \mathrm{~W}$ cells. (A) Cell viability was evaluated using a MTT assay. (B) Cell apoptosis was determined using a cell death detection ELISA ${ }^{\text {plus }}$ kit. (C) Expression levels of Bcl-2, BAX, and cleaved caspase 3 were detected using western blotting. (D and E) Semi-quantification of (D) the BAX/Bcl-2 ratio and (E) cleaved caspase 3 expression levels from part C. GAPDH was used as the internal loading standard. Each data point was normalized to the PBS group. Data are presented as the mean \pm SD. ${ }^{*} \mathrm{P}<0.05,{ }^{* *} \mathrm{P}<0.01,{ }^{* * *} \mathrm{P}<0.001,{ }^{* * * *} \mathrm{P}<0.0001$. LIF, leukemia inhibitory factor; $\mathrm{H}_{2} \mathrm{O}_{2}$, hydrogen peroxide.

post-injection. To determine the functional and morphological changes of cone cells in the retina, ERGs and immunofluorescent staining were performed. Photoreceptors can be divided into rods and cones; among the four different opsin molecules found in humans, one type is found in rods and is responsible for low-light vision, while the other three types are found in cones and provide color vision by responding to red $(558 \mathrm{~nm})$, green $(531 \mathrm{~nm})$, and blue $(419 \mathrm{~nm})$ wavelengths (30). Cone cells are often classified into long (L), medium (M) and short (S) wavelength cones; however, mice only have two types: an $\mathrm{M}$ cone to detect green wavelengths and an $\mathrm{S}$ cone for blue wavelengths (30). Therefore, the present study used white, green, and blue light stimulation for ERG examinations to detect the function of the whole cone, $\mathrm{M}$ cone, and $\mathrm{S}$ cone cells. The morphological changes in $\mathrm{M}$ - and S-cones were also detected using their respective antibodies. Results from the ERG demonstrated that compared with the eyes in the normal control group, the function of $\mathrm{M}$ - and S- cones in the eyes treated with the intravitreal injection of PBS followed by light-induced damage was reduced to $30 \%$. By contrast, the intravitreal injection of LIF recovered the $\mathrm{M}$ - and S-cones to $80-90 \%$ of their normal function. The morphological changes that occurred in $\mathrm{M}$ - and S-cones demonstrated the same trend as the functional changes. These findings suggest that LIF treatment may protect both the function and morphology of cones cells from lightinduced damage.

Light-induced oxidative damage is a major stressor that generally subverts life of aerobic species, key adaptive mechanisms to cope with oxidative damage are the expression of a multitude of genes, including those involved in cell survival. Importantly, it can also be sensed via changes in metabolite levels and generation of ROS by mitochondria. A previous study reported that a single intravitreal injection of LIF activated downstream signaling pathways, including STAT3, ERK1/2, and AKT (31); however, despite studies having investigated the activation of STAT3 and ERK1/2 
A

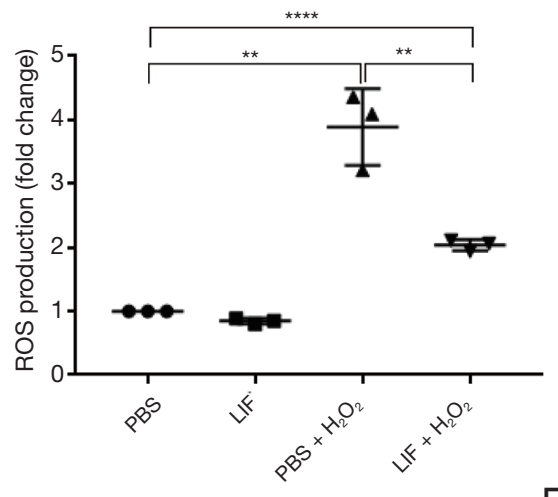

$\mathrm{E}$

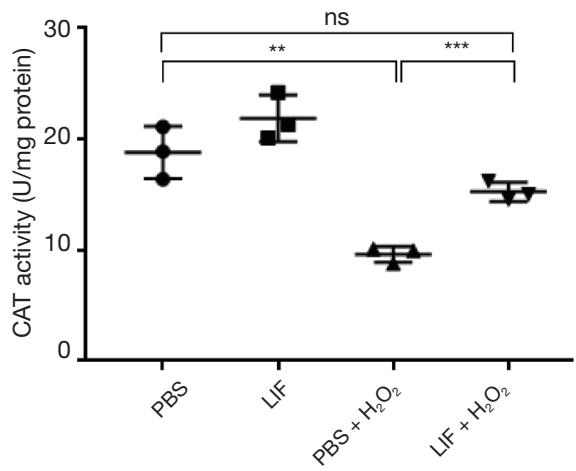

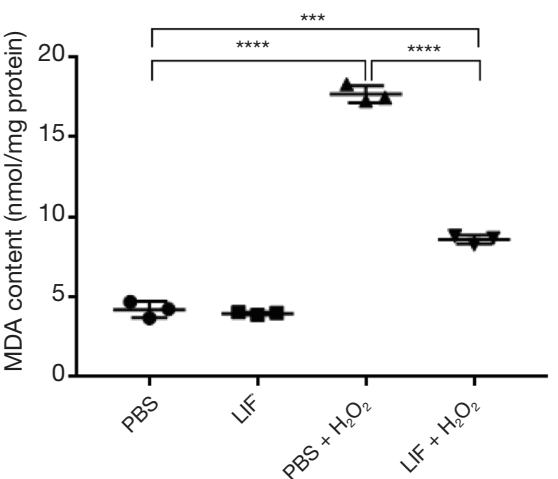

B

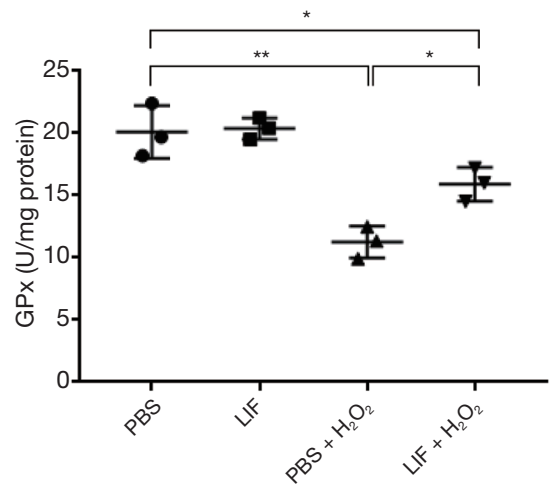

C

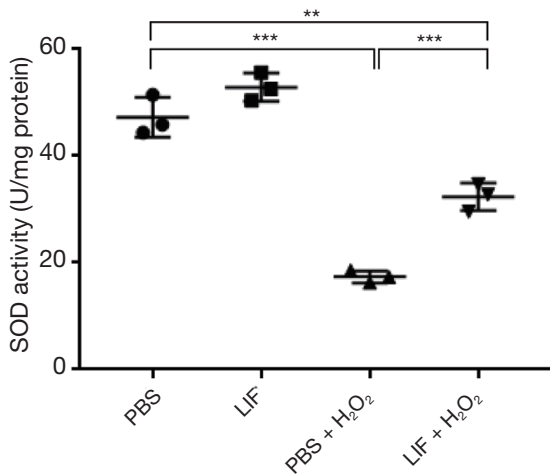

Figure 6 Effects of LIF on $\mathrm{H}_{2} \mathrm{O}_{2}$-triggered oxidative stress in $661 \mathrm{~W}$ cells. (A) Intracellular ROS generation in $661 \mathrm{~W}$ cells was detected using a DCFH-DA assay. Each data point was normalized to the vehicle control (PBS group). (B-E) ELISAs were used to analyze (B) the MDA content and the activities of (C) SOD, (D) CAT, and (E) GPx. Data are presented as the mean $\pm \mathrm{SD}$. ${ }^{*} \mathrm{P}<0.05,{ }^{* *} \mathrm{P}<0.01,{ }^{* * *} \mathrm{P}<0.001$, ${ }^{* * * *} \mathrm{P}<0.0001$. LIF, leukemia inhibitory factor; ROS, reactive oxygen species; $\mathrm{H}_{2} \mathrm{O}_{2}$, hydrogen peroxide.

in Müller cells, the activation in photoreceptors has yet to be elucidated (32). In the present study, it was observed that the intravitreal injection of LIF resulted in STAT3 activation in the retina. To further investigate its molecular mechanism, differentially expressed genes in the retina between the LIF and PBS groups subjected to light damage were detected using microarray analysis (data not shown), and the expression of apoptosis- and proliferation-related genes were validated by RT-qPCR. The observed increased mRNA expression levels of SOD, CAT, and GPx1 validated the occurrence of light-induced oxidative damage; the increased mRNA expression of STAT3, SOCS3, and JAK3 confirmed the LIF-induced protective role of the JAK/ STAT3 pathway against light-induced oxidative damage; and the increased expression levels of the anti-apoptotic genes BCL2A1D and ATF3 and the pro-proliferative genes GADD45A and PARP12, alongside the decreased expression of the pro-apoptotic gene DDIT4 and the anti-proliferative gene GZMM, indicated that LIF-induced activation of the JAK/STAT3 signaling pathway may promote anti-apoptotic and pro-proliferative functions that protect the retina from oxidative damage.

To further confirm the protective effect of LIF against light damage in vitro, an oxidative damage cell model was used. Treatment with $\mathrm{H}_{2} \mathrm{O}_{2}$ is a commonly used strategy to study oxidative stress in a variety of cell lines (33). Hence, $\mathrm{H}_{2} \mathrm{O}_{2}$-induced $661 \mathrm{~W}$ cone cells were used as an in vitro model to study the biological function of photoreceptors. The findings of the present study demonstrated that $\mathrm{H}_{2} \mathrm{O}_{2}$ could decrease the cell viability and increase apoptosis in $661 \mathrm{~W}$ cells, while the addition of LIF treatment alleviated the $\mathrm{H}_{2} \mathrm{O}_{2}$-induced apoptosis. Previous studies have reported that LIF is involved in the apoptosis of astrocytes, cholangiocarcinoma cells, and podocytes (34-36); however, 
A

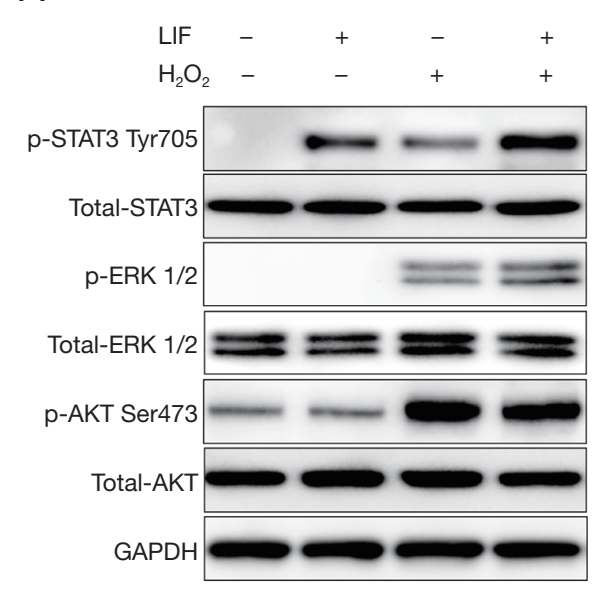

D

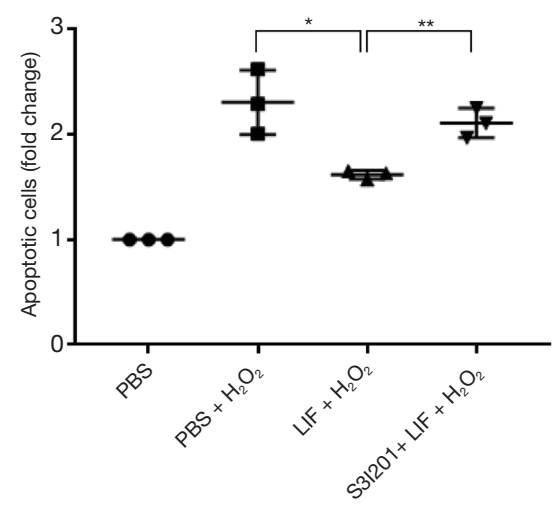

B

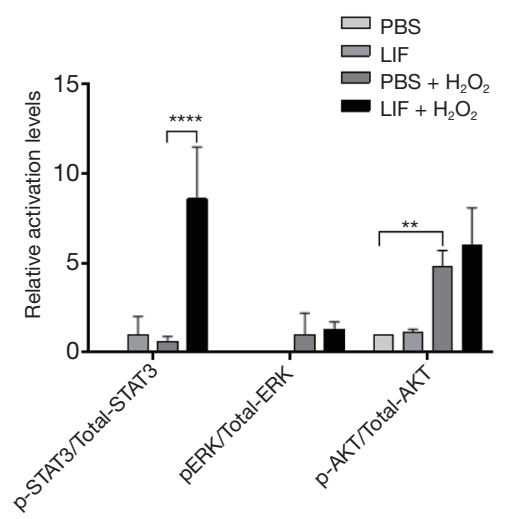

E

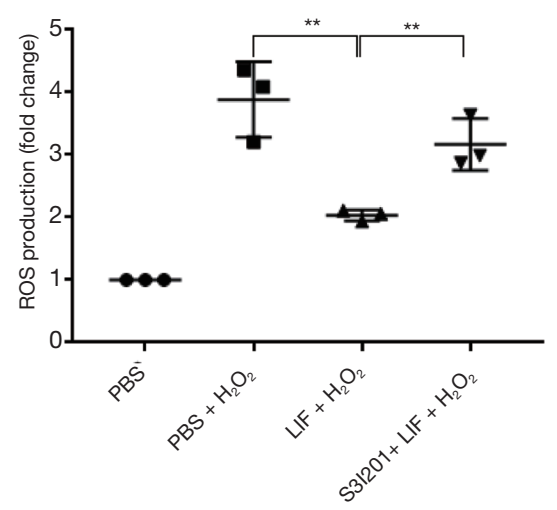

Figure 7 Activation of the STAT3 signaling pathway contributes to the protective role of $\mathrm{LIF}$ in $\mathrm{H}_{2} \mathrm{O}_{2}$-induced damage in $661 \mathrm{~W}$ cells. (A) Expression levels of p-STAT3, p-ERK1/2, and p-AKT in $661 \mathrm{~W}$ cells treated with various treatments were detected using western blotting. (B) Semi-quantification of the activation of STAT3, ERK1/2, and AKT in $661 \mathrm{~W}$ cells from part A. (C) Cell viability of $661 \mathrm{~W}$ cells treated with various treatment was analyzed using a MTT assay. (D) Cell apoptosis was detected using a cell death detection ELISA ${ }^{\text {plus }}$ kit. (E) ROS production was measured using a DCFH-DA assay. Data are presented as the mean $\pm \mathrm{SD}$. ${ }^{*} \mathrm{P}<0.05,{ }^{* *} \mathrm{P}<0.01,{ }^{* * * *} \mathrm{P}<0.0001$. LIF, leukemia inhibitory factor; ROS, reactive oxygen species; $\mathrm{H}_{2} \mathrm{O}_{2}$, hydrogen peroxide; S3I201, STAT3 inhibitor.

the relationship between LIF and apoptosis in cone cells has yet to be reported. To the best of our knowledge, there have been no other studies that have reported on the protective effect of LIF against apoptosis in cone cells; our study thus provides valuable and novel insight into the potential role of LIF in $\mathrm{H}_{2} \mathrm{O}_{2}$-induced apoptotic processes in cone cells.

Accumulating research has indicated that oxidative stress serves a crucial role in the pathogenesis of AMD (37). Oxidative stress is thought to be a major contributor to photoreceptor damage, which may eventually lead to a loss of vision (38). These processes are involved in the formation of ROS, and increasing evidence has demonstrated that oxidative stress-induced ROS production exceeds the limits of scavenging, which leads to an imbalance between the oxidative and antioxidant systems (39). As a prominent antioxidant enzyme, SOD can protect cells from oxidative damage (40). To investigate whether LIF participated in the oxidative stress process, the effects of LIF on oxidative stress were evaluated by determining the levels of ROS production, MDA content, and the activities of SOD, CAT and GPx. The results demonstrated that treatment with LIF reduced the $\mathrm{H}_{2} \mathrm{O}_{2}$-induced production of ROS and MDA content, indicating that LIF may exert antioxidant activity in cone cells in response to oxidative damage. Also, LIF treatment increased the activity of SOD, CAT, and GPx in order to avoid peroxidative damage. Altogether, we can surmise from 
these findings that LIF may reduce $\mathrm{H}_{2} \mathrm{O}_{2}$-induced oxidative damage through promoting antioxidant activities.

To validate the role of JAK/STAT3 signaling in the protective effect of LIF against oxidative damage in $661 \mathrm{~W}$ cone cells, the phosphorylation of STAT3 in $661 \mathrm{~W}$ cells under different treatments was detected; a significant increase in the activation of STAT3 was observed in $\mathrm{H}_{2} \mathrm{O}_{2}$ induced $661 \mathrm{~W}$ cells pretreated with LIF. Subsequently, the use of the STAT3 inhibitor S3I201 to block the function of STAT3 inhibited the protective effects of LIF on $\mathrm{H}_{2} \mathrm{O}_{2}$ induced apoptosis and ROS production. Collectively, these findings suggest that LIF may prevent $\mathrm{H}_{2} \mathrm{O}_{2}$-induced apoptosis and oxidative stress through targeting STAT3 signaling in photoreceptor cone cells.

In conclusion, these findings indicate that LIF may protect cone cells against oxidative damage through its anti-apoptotic and antioxidant activity, by targeting, at least in part, the STAT3 signaling pathway. Inhibition of this pathway provides a potential therapeutic strategy to ameliorate retinal oxidative stress that occurs due to prolonged light exposure or other factors, and help prevent the progression of AMD.

\section{Acknowledgments}

Funding: This study was supported by grants provided by the National Natural Science Foundation of China (no. 81800830), the Key Research and Development and Promotion Project (Science and Technology) Program of Henan Province (no. 192102310077), and the Science and Technology Project pf The Health Planning Committee of Sichuan (no. 18PJ119).

\section{Footnote}

Reporting Checklist: The authors have completed the ARRIVE reporting checklist. Available at http://dx.doi. org/10.21037/atm-20-8040

Data Sharing Statement: Available at http://dx.doi. org/10.21037/atm-20-8040

Conflicts of Interest: All authors have completed the ICMJE uniform disclosure form (available at http://dx.doi. org/10.21037/atm-20-8040). The authors have no conflicts of interest to declare.

Ethical Statement: The authors are accountable for all aspects of the work in ensuring that questions related to the accuracy or integrity of any part of the work are appropriately investigated and resolved. All procedures were in accordance with the National Institutes of Health Guide for the Care and Use of Laboratory Animals. The current study was approved by the ethics committee of the First Affiliated Hospital of Zhengzhou University (Zhengzhou, China).

Open Access Statement: This is an Open Access article distributed in accordance with the Creative Commons Attribution-NonCommercial-NoDerivs 4.0 International License (CC BY-NC-ND 4.0), which permits the noncommercial replication and distribution of the article with the strict proviso that no changes or edits are made and the original work is properly cited (including links to both the formal publication through the relevant DOI and the license). See: https://creativecommons.org/licenses/by-nc-nd/4.0/.

\section{References}

1. Hanus J, Zhao F, Wang S. Current therapeutic developments in atrophic age-related macular degeneration. Br J Ophthalmol 2016;100:122-7.

2. Pawlowska E, Szczepanska J, Koskela A, et al. Dietary polyphenols in age-related macular degeneration: protection against oxidative stress and beyond. Oxid Med Cell Longev 2019;2019:9682318.

3. Chiras D, Kitsos G, Petersen MB, et al. Oxidative stress in dry age-related macular degeneration and exfoliation syndrome. Crit Rev Clin Lab Sci 2015;52:12-27.

4. Kaarniranta K, Pawlowska E, Szczepanska J, et al. Role of mitochondrial DNA damage in ROS-mediated pathogenesis of Age-Related Macular Degeneration (AMD). Int J Mol Sci 2019;20:2374.

5. Dulull NK, Dias DA, Thrimawithana TR et al. L-Sulforaphane confers protection against oxidative stress in an in vitro model of Age-Related Macular Degeneration. Curr Mol Pharmacol 2018;11:237-53.

6. Khandhadia S, Lotery A. Oxidation and age-related macular degeneration: insights from molecular biology. Expert Rev Mol Med 2010;12:e34.

7. Ao J, Wood JP, Chidlow G, et al. Retinal pigment epithelium in the pathogenesis of age-related macular degeneration and photobiomodulation as a potential therapy? Clin Exp Ophthalmol 2018;46:670-86.

8. Bardak H, Uğuz AC, Bardak Y. Protective effects of melatonin and memantine in human retinal pigment epithelium (ARPE-19) cells against 2-ethylpyridine- induced 
oxidative stress: implications for age-related macular degeneration. Cutan Ocul Toxicol 2018;37:112-20.

9. George AK, Singh M, Homme RP, et al. A hypothesis for treating inflammation and oxidative stress with hydrogen sulfide during age-related macular degeneration. Int J Ophthalmol 2018;11:881-7.

10. Nowak JZ. Oxidative stress, polyunsaturated fatty acidsderived oxidation products and bisretinoids as potential inducers of CNS diseases: focus on age-related macular degeneration. Pharmacol Rep 2013;65:288-304.

11. Jaadane I, Boulenguez P, Chahory S, et al. Retinal damage induced by commercial light emitting diodes (LEDs). Free Radic Biol Med 2015;84:373-84.

12. Imai S, Inokuchi $Y$, Nakamura $S$, et al. Systemic sdministration of a free radical scavenger, edaravone, protects against light-induced photoreceptor degeneration in the mouse retina. Eur J Pharmacol 2010;642:77-85.

13. Taga T. Gp130, a shared signal transducing receptor component for hematopoietic and neuropoietic cytokines. J Neurochem 1996;67:1-10.

14. Kunisada K, Hirota H, Fujio Y, et al. Activation of JAK-STAT and MAP kinases by leukemia inhibitory factor through gp130 in cardiac myocytes. Circulation 1996;94:2626-32.

15. Murphy M, Reid K, Hilton DJ, et al. Generration of sensory neurons is stimulated by leukemia inhibitory factor. Proc Natl Acad Sci U S A 1991;88:3498-501.

16. Azari MF, Profyris C, Karnezis T, et al. Leukemia inhibitory factor arrests oligodendrocyte death and demyelination in spinal cord injury. J Neuropathol Exp Neurol 2006;65:914-29.

17. Samardzija M, Wenzel A, Aufenberg S, et al. Differential role of Jak-STAT signaling in retinal degenerations. FASEB J 2006;20:2411-13.

18. Bürgi S, Samardzija M, Grimm C. Endogenous leukemia inhibitory factor protects photoreceptor cells against lightinduced degeneration. Mol Vis 2009;15:1631-7.

19. Ueki Y, Wang J, Chollangi S, et al. STAT3 activation in photoreceptors by leukemia inhibitory factor is associated with protection from light damage. J Neurochem 2008;105:784-96.

20. DuVal MG, Allison WT. Impacts of the retinal environment and photoreceptor and type on functional regeneration. Neural Regen Res 2017;12:376-9.

21. Bringmann A, Reichenbach A. Role of Muller cells in retinal degenerations. Front Biosci 2001;6:E72-92.

22. Joly S, Lange C, Thiersch M, et al. Leukemia inhibitory factor extends the lifespan of injured photoreceptors in vivo. J Neurosci 2008;28:13765-74.

23. Okano K, Maeda A, Chen Y, et al. Retinal cone and rod photoreceptor cells exhibit differential susceptibility to light-induced damage. J Neurochem 2012;121:146-56.

24. Li S, Lee J, Zhou Y, et al. Fatty acid transport protein 4 (FATP4) prevents light-induced degeneration of cone and rod photoreceptors by inhibiting RPE65 isomerase. J Neurosci 2013;33:3178-89.

25. Wiley LA, Burnight ER, DeLuca AP, et al. cGMP production of patient-specific iPSCs and photoreceptor precursor cells to treat retinal degenerative blindness. Sci Rep 2016;6:30742.

26. Joly S, Pernet V, Chemtob S, et al. Neuroprotection in the juvenile rat model of light-induced retinopathy: evidence suggesting a role for FGF-2 and CNTF. Invest Ophthalmol Vis Sci 2007;48:2311-20.

27. Qin Z, Kidd AR 3rd, Thomas JL, et al. FGF signaling regulates rod photoreceptor cell maintenance and regeneration in zebrafish. Exp Eye Res 2011;93:726-34.

28. LaVail MM, Faktorovich EG, Hepler JM, et al. Basic fibroblast growth factor protects photoreceptors from light-induced degeneration in albino rats. Ann N Y Acad Sci 1991;638:341-7.

29. LaVail MM, Unoki K, Yasumura D, et al. Multiple growth factors, cytokines, and neurotrophins rescue photoreceptors from the damaging effects of constant light. Proc Natl Acad Sci U S A 1992;89:11249-53.

30. Molday RS, Moritz OL. Photoreceptors at a glance. J Cell Sci 2015;128:4039-45.

31. Ueki Y, Le YZ, Chollangi S, et al. Preconditioninginduced protection of photoreceptors requires activation of the signal-transducing receptor gp130 in photoreceptors. Proc Natl Acad Sci U S A 2009;106:21389-94.

32. Pannicke T, Wagner L, Reichenbach A, et al. Electrophysiological characterization of Müller cells from the ischemic retina of mice deficient in the leukemia inhibitory factor. Neurosci Lett 2018;670:69-74.

33. Sies $\mathrm{H}$. Role of metabolic $\mathrm{H} 2 \mathrm{O} 2$ generation: redox signaling and oxidative stress. J Biol Chem 2014;289:8735-41.

34. Huo L, Fan Y, Wang H. Leukemia Inhibitory Factor Receptor Is Involved in Apoptosis in Rat Astrocytes Exposed to Oxygen-Glucose Deprivation. Biomed Res Int 2019;2019:1613820.

35. Morton SD, Cadamuro M, Brivio S, et al. Leukemia inhibitory factor protects cholangiocarcinoma cells from drug-induced apoptosis via a PI3K/AKT- dependent Mcl1 activation. Oncotarget 2015;6:26052-64.

36. Xu J, Li Z, Xu P, et al. Protective effects of leukemia 
inhibitory factor against oxidative stress during high glucose-induced apoptosis in podocytes. Cell Stress Chaperones 2012;17:485-93.

37. Fanjul-Moles ML, López-Riquelme GO. Relationship between Oxidative Stress, Circadian Rhythms, and AMD. Oxid Med Cell Longev 2016;2016:7420637.

38. Lajko M, Cardona HJ, Taylor JM, et al. Photoreceptor oxidative stress in hyperoxia-induced proliferative retinopathy accelerates $\mathrm{rd} 8$ degeneration. PLoS One

Cite this article as: Dong S, Zhen F, Xu H, Li Q, Wang J. Leukemia inhibitory factor protects photoreceptor cone cells against oxidative damage through activating JAK/STAT3 signaling. Ann Transl Med 2021;9(2):152. doi: 10.21037/atm20-8040 2017;12:e0180384.

39. Newsholme P, Cruzat VF, Keane KN, et al. Molecular mechanisms of ROS production and oxidative stress in diabetes. Biochem J 2016;473:4527-50.

40. Poprac P, Jomova K, Simunkova M, et al. Targeting Free Radicals in Oxidative Stress-Related Human Diseases. Trends Pharmacol Sci 2017;38:592-607.

(English Language Editor: J. Gray) 